\title{
The Effect of Chloride Ions on the Activity of Cerussite Surfaces
}

\author{
Qicheng Feng ${ }^{1}$, Shuming Wen ${ }^{1, *}$, Qinbo Cao ${ }^{1, *}$, Jiushuai Deng ${ }^{1}$ and Wenjuan Zhao ${ }^{2}$ \\ 1 State Key Laboratory of Complex Nonferrous Metal Resources Clean Utilization, \\ Faculty of Land Resource Engineering, Kunming University of Science and Technology, \\ Kunming 650093, China; fqckmust@126.com (Q.F.); dengshuai689@126.com (J.D.) \\ 2 Kunming Metallurgical Research Institute, Kunming 650031, China; wenjuan19880718@163.com \\ * Correspondence: shmwen@126.com (S.W.); cabdxx@163.com (Q.C.); Tel.: +86-871-515-3445 (S.W.) \\ Academic Editor: Athanasios Godelitsas \\ Received: 16 July 2016; Accepted: 30 August 2016; Published: 6 September 2016
}

\begin{abstract}
Chloride ions were found to potentially increase activity of cerussite surfaces. Dissolution experiments, zeta potential measurements, X-ray photoelectron spectroscopy (XPS) studies, and density functional theory (DFT) computation were conducted in this study. Dissolution experiments showed that the lead ion concentrations in the $\mathrm{NaCl}$ solution system were lower than those in the deionized water system and that the lead ion concentrations in $\mathrm{NaCl}+\mathrm{Na}_{2} \mathrm{~S}$ aqueous systems decreased by approximately one order of magnitude compared with that in $\mathrm{Th}_{2} \mathrm{Na}_{2} \mathrm{~S}$ system alone. Results of zeta potential measurements revealed that the pretreatment with chloride ions of cerussite caused a more positive zeta potential than that without chloride ions. XPS analysis results indicated that the number of lead ions on the mineral surface increased after cerussite was treated with chloride ions. Results of DFT computation implied that the number of lead atoms on the mineral surface increased and that the activity improved after $\mathrm{PbCl}^{+}$was adsorbed onto the cerussite surface. The contribution of chloride ions to the activity on the mineral surface is attributed to the increase in the number of active sites and enhancement in the activity of these sites, resulting in improved sulfidization and flotation performance.
\end{abstract}

Keywords: cerussite; active sites; chloride ions; adsorption; DFT

\section{Introduction}

Lead oxide minerals are an important lead resource, and cerussite is a typical lead oxide mineral. With increasing lead consumption, lead sulfide ores cannot meet the requirements of lead smelting; lead oxide resources must be efficiently utilized to address the imbalance between metal lead supply and demand [1-3]. Sulfidization flotation has been the most commonly and commercially used method for concentration and pretreatment of lead oxide minerals, and the most critical stage in this process is sulfidization [4-6]. Numerous sulfidization techniques including mechanochemical sulfidization $[7,8]$, hydrothermal sulfidization [2,9], and sulfidization roasting [1,10] have been attempted to sulfidize lead oxide materials. However, only the surface sulfidization method is available because of technical and economic conditions. Nevertheless, this method continues to exhibit deficiencies, such as low sulfidization efficiency, weak sulfidization products, abundant dosage of sulfidization agents and collectors, as well as low lead recovery. Thus, surface sulfidization reinforcement is crucial to concentrate lead oxide minerals by flotation.

Flotation reagents cannot be adsorbed onto mineral surfaces with a homogeneous distribution, and they initially interact with the active sites on the mineral surface. Therefore, the number and activity of active sites on the mineral surface are vital to the surface sulfidization method. Adding chloride ions prior to sulfidization can greatly enhance the flotation recovery of cerussite [11]. 
This excellent flotation performance of cerussite treated with chloride ions was ascribed to the strong coordination of chloride ions to lead ions. The chloride ion concentrations determine the distributions of various lead chloride complexes in solutions, and $\mathrm{PbCl}^{+}$is the dominant species in solutions at low concentrations of chloride ions. In this case, it attaches more readily to the surface of cerussite through ligands than $\mathrm{Pb}^{2+}$, thereby increasing the number of active sites on the mineral surface and improving the subsequent sulfidization. Chloride ions also possess a small ionic radius, strong penetrability, and strong adsorption capacity onto metals; thus, chloride ions can combine with lead on the cerussite surface to form lead chloride complexes and even pass through the mineral surface to exchange carbonate ions $\left(\mathrm{CO}_{3}{ }^{2-}\right)$ with the inner cerussite, which can further increase the activity on the cerussite surface [11-13]. Adding chloride ions prior to sulfidization can activate the cerussite surface and reinforce the sulfidization of cerussite.

The contribution of chloride ions to the sulfidization flotation of cerussite has been reported in detail through various experiments and measurements as well as theoretical analysis in our previous publication [11], but the surface properties of cerussite treated with chloride ions remain unclear. In the present study, dissolution experiments, zeta potential measurements, X-ray photoelectron spectroscopy (XPS) studies, and density functional theory (DFT) computation were conducted to investigate the effect of chloride ions on activity of cerussite surface and to further reveal the nature of their contribution to surface sulfidization reinforcement.

\section{Materials and Methods}

\subsection{Materials and Reagents}

The cerussite mineral samples obtained from the Lanping lead-zinc mine (Lanping, Yunnan, China) were crushed and handpicked to remove various impurities such as calcite and quartz. The purified minerals were dry ground in an agate mortar and screened to $-74+45 \mu \mathrm{m}$ and $-5 \mu \mathrm{m}$ sized fractions. The $-74+45 \mu \mathrm{m}$ mineral particles were used in the dissolution experiments and XPS analysis, and the $-5 \mu \mathrm{m}$ particles were used for zeta potential measurements. The chemical analysis and X-ray diffraction analysis results showed that the samples were of high purity with only minor impurities. All of the reagents used in this study were of analytical grade. Pure deionized water was used throughout the experiment.

\subsection{Dissolution Experiments}

Dissolution experiments were conducted after dispersing $5 \mathrm{~g}$ of the cerussite samples into $500 \mathrm{~mL}$ of aqueous phase, which was placed in a thermostatically controlled water bath. The suspensions were magnetically stirred at $650 \mathrm{rpm}$, and the solution was maintained at $298 \mathrm{~K}$. Five milliliters of the resultant solution was accurately withdrawn at specific time intervals for each dissolution system, and the solid-liquid separation was performed using a centrifuge. The separated liquid was collected to analyze the total lead concentrations by means of inductively coupled plasma-atomic emission spectrometry (ICPS-1000II, Shimadzu, Kyoto, Japan), and the maximum standard deviation for measurement of each liquid sample was within $\pm 2 \%$. Four sets of dissolution experiments including the pretreatment of cerussite samples with and without chloride ions were conducted in the absence or presence of $\mathrm{Na}_{2} \mathrm{~S} \cdot 9 \mathrm{H}_{2} \mathrm{O}$ in this study.

\subsection{Zeta Potential Measurements}

Zeta potentials of the samples were obtained by using a zeta potential analyzer instrument (ZetaPlus, Brookhaven, New York, NY, USA). The mineral suspension (0.01\% mass fraction) was dispersed in a beaker magnetically stirred for a determined time in the presence of the desired concentrations of sodium chloride at a determined $\mathrm{pH}$ value, which was regulated through $0.10 \mathrm{~mol} \cdot \mathrm{L}^{-1} \mathrm{NaOH}$ or $0.10 \mathrm{~mol} \cdot \mathrm{L}^{-1} \mathrm{HNO}_{3}$ solutions. After $10 \mathrm{~min}$ of settling of the resultant suspensions, the $\mathrm{pH}$ value was measured and recorded, and the fine mineral particles were transferred 
to the measurement vessel for zeta potential measurements at room temperature. The zeta potential of each sample was measured three times with the maximum standard deviation of $\pm 2.0 \mathrm{mV}$, and the average was reported as the final value in the present study.

\subsection{XPS Analysis}

The measured samples were obtained at the desired conditions described in Section 2.2 for XPS analysis. The XPS measurements were carried out by using a PHI5000 Versa Probe II (PHI5000, ULVAC-PHI, Chigasaki, Japan) equipped with a monochromatic $\mathrm{Al} \mathrm{K} \alpha \mathrm{X}$-ray source. The survey scan of the analyzed sample was conducted to identify the chemical components, and a high-resolution scan on a specific element was then performed. Subsequently, the MultiPak Spectrum software was used to calculate and analyze the spectra and surface atomic ratios of measured samples, and the carbon 1s spectral peak was used to calibrate all of the measured spectra.

\subsection{Computational Methods}

All computations were based on the cerussite crystal structure reported by Antao and Hassan [14]. The cerussite (110) surface was used for surface structure and property calculation. Figure 1 illustrates the slab model of perfect cerussite (110) surface, which contained $20 \AA$ atomic and $20 \AA$ vacuum layers. The computations were conducted through first-principle calculations based on DFT as implemented in Cambridge Serial Total Energy Package (CASTEP) developed by Payne et al. [15]. The valence electron configurations involved in the present calculation included $\mathrm{C} 2 \mathrm{~s}^{2} 2 \mathrm{p}^{2}, \mathrm{O} 2 \mathrm{~s}^{2} 2 \mathrm{p}^{4}, \mathrm{~Pb}^{5} \mathrm{~d}^{10} 6 \mathrm{~s}^{2} 6 \mathrm{p}^{2}$, and $\mathrm{Cl} 3 \mathrm{~s}^{2} 3 \mathrm{p}^{5}$. The exchange-correlation functional used was the generalized gradient approximation developed by Perdew et al. [16] for solids. The kinetic energy cutoff of $340 \mathrm{eV}$ for the plane-wave basis was employed throughout this study. The Brillouin zone was sampled with Monkhorst-Pack special k-points of a $4 \times 3 \times 1$ grid for all the structure calculations. Pulay density mixing method was employed for self-consistent electronic minimization. The energy, force, and displacement tolerance was $1.0 \times 10^{-5} \mathrm{eV} /$ atom, $3.0 \times 10^{-2} \mathrm{eV} / \AA$, and $1.0 \times 10^{-3} \AA$, respectively.

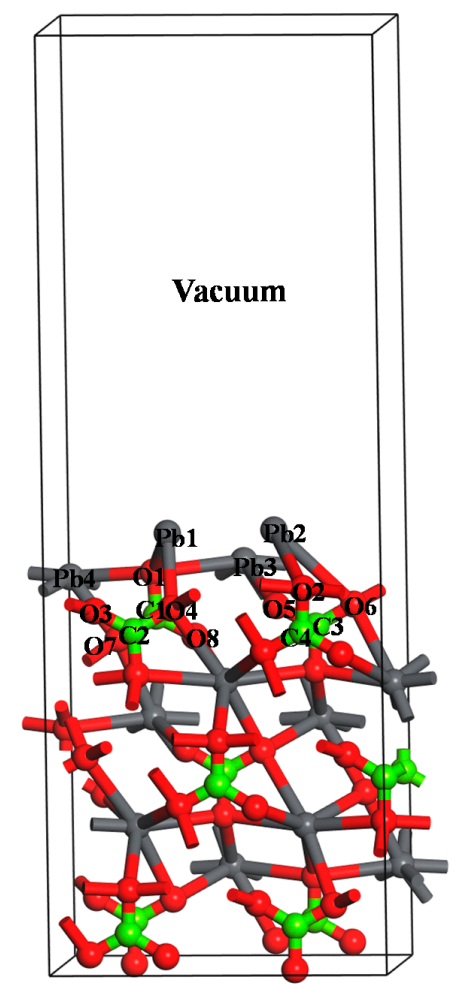

Figure 1. Slab model of perfect cerussite (110) surface. 


\section{Results and Discussion}

\subsection{Dissolution Experiments}

As a semi-soluble salt mineral with a standard solubility product constant of $7.40 \times 10^{-14}$ [17-19], there are a great number of dissolved lead ions in the pulp solution released from the cerussite mineral lattice, which will significantly affect the lead species balance in the mineral/solution interface. Meanwhile, such a dissolution process will render the adsorbed species of flotation reagents away from the mineral surface in the subsequent process, and it is also associated with the large consumption of flotation reagents. Thus, the dissolution properties of cerussite become evident in analyzing its subsequent sulfidization and flotation behavior. To investigate the effect of chloride ions on the dissolution properties of cerussite, we discussed the dissolved lead ion concentrations of cerussite in various systems as a function of time. The results are shown in Table 1.

Table 1. Dissolved lead ion concentrations of cerussite in various systems as a function of time.

\begin{tabular}{ccccc}
\hline \multirow{2}{*}{ Time, $\min$} & \multicolumn{3}{c}{ Concentrations of $\mathbf{P b}$ in Various Systems, $\mathbf{~ m g} / \mathbf{L}$} \\
\cline { 2 - 5 } & Deionized Water & $\mathbf{N a C l}$ & $\mathbf{N a}_{\mathbf{2}} \mathbf{S}$ & $\mathbf{N a C l}+\mathbf{N a}_{\mathbf{2}} \mathbf{S}$ \\
\hline 1 & 1.5166 & 1.4208 & 0.2579 & 0.0382 \\
3 & 1.9698 & 1.7309 & 0.2356 & 0.0289 \\
6 & 2.2364 & 2.0611 & 0.2033 & 0.0297 \\
10 & 2.6481 & 2.7033 & 0.3154 & 0.0187 \\
15 & 3.1456 & 2.9109 & 0.1197 & 0.0384 \\
20 & 3.2942 & 3.1346 & 0.1245 & 0.0456 \\
30 & 3.3803 & 3.2844 & 0.2336 & 0.0353 \\
45 & 3.6342 & 3.1327 & 0.1355 & 0.0322 \\
60 & 3.8023 & 3.0532 & 0.1639 & 0.0246 \\
\hline
\end{tabular}

The solubility of cerussite differed in various solution systems (see Table 1). The lead ion concentrations gradually increased with the dissolution time in deionized water system, which followed the dissolution behavior of carbonate minerals [20]. For the $\mathrm{NaCl}$ solution system, the lead ion concentration was similar in magnitude to that presented in deionized water, and the lead ion concentration also increased with the dissolution time within 30 min of dissolution. It began to decrease after $30 \mathrm{~min}$, which indicated that the dissolution rate of lead ions was higher than their adsorption rate on the mineral surface within $30 \mathrm{~min}$, whereas it reversed after 30 min of dissolution. Combined with the result shown in our previous publication [11], the dominant species of lead chloride complexes presented in the solution is $\mathrm{PbCl}^{+}$when the concentration of chloride ions was low, and $\mathrm{PbCl}^{+}$has better affinity for attaching to the cerussite surface than $\mathrm{Pb}^{2+}$. Thus, the adsorption capacity of $\mathrm{Pb}$ species onto the mineral surface in the $\mathrm{NaCl}$ solution system is stronger than that in deionized water. The lead ion concentrations in the $\mathrm{NaCl}$ solution system were lower than those in the deionized water system (see Table 1), implying that more lead ions existed on the mineral surface in the $\mathrm{NaCl}$ solution system according to the mass balance of lead. The active sites on the cerussite surface were lead ions during the sulfidization flotation of the surface; thus, the number of active sites increased on the cerussite surface after pretreatment with chloride ions, and this increase increased the likelihood of subsequent sulfidization and flotation. This finding further confirms the result of our previous study [11].

The change in lead ion concentrations as a function of time in $\mathrm{Na}_{2} \mathrm{~S}$ and $\mathrm{NaCl}+\mathrm{Na}_{2} \mathrm{~S}$ aqueous systems were exhibited to further verify the increased activity on the mineral surface. The lead ion concentrations drastically dropped in the $\mathrm{Na}_{2} \mathrm{~S}$ system compared with the deionized water system (see Table 1). This decrease is attributed to the formation of lead sulfide species on the mineral surface through the interaction of sulfide ions with dissolved lead ions in pulp solutions. The formed lead sulfide films would screen or reduce the dissolution of cerussite, but it could not be uniformly 
distributed onto the mineral surface. Thus, some lead ions were dissolved into the pulp solution. After the cerussite was pretreated with chloride ions, the lead ion concentrations in the aqueous phase decreased by approximately one order of magnitude compared with that in the $\mathrm{Na}_{2} \mathrm{~S}$ system alone. This result is attributed to the favorable condition created by chloride ions. The increased number of active sites on the mineral surface provided more binding sites to subsequent sulfide ions; thus, more sulfide ions were adsorbed onto the mineral surface to form a greater number of lead sulfide species, and these species were probably distributed onto the mineral surface evenly and densely. The dissolution of the cerussite surface coated with the formed lead sulfide species through chloride ions pretreatment significantly decreased. Thus, the occurrence of hydrophobic lead xanthate species formed on the cerussite surface through mineral dissolution could be prevented or reduced.

\subsection{Zeta Potential Measurements}

The zeta potential, as an in situ surface-sensitive technique, is frequently used to describe the interaction of flotation reagents and mineral surface [21,22]. Electrokinetic potential measurements were used to further characterize the effect of chloride ions on activity of cerussite surface. Figure 2 presents the zeta potential of cerussite in the absence or presence of chloride ions as a function of pH values.

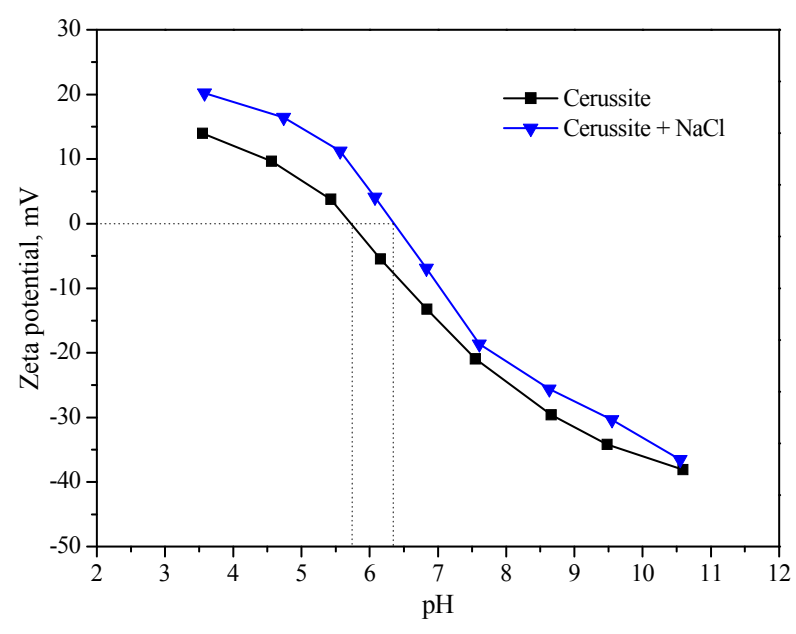

Figure 2. Zeta potential of cerussite as a function of $\mathrm{pH}$.

The isoelectric point (IEP) value of cerussite without pretreatment of chloride ions was obtained as about $\mathrm{pH} 5.7$ (see Figure 2), which was located at the values of $\mathrm{pH} 4.0$ and 6.5 according to previous research [23-25]. The zeta potential decreased with the increase in $\mathrm{pH}$ values. The zeta potential was positive for $\mathrm{pH}$ values lower than $\mathrm{pH} 5.7$ but negative for $\mathrm{pH}$ values higher than $\mathrm{pH}$ 5.7. After cerussite was added into the $\mathrm{NaCl}$ solution, the zeta potential became more positive within the entire $\mathrm{pH}$ range, and the IEP value increased from $\mathrm{pH} 5.7$ to 6.4 (see Figure 2). This finding indicated that the number of positively charged species increased on the mineral surface, and the increased species may be lead species that resulted from migration between the mineral lattice and aqueous solutions. This deduction was attributed to the following reasons. First, chloride ions added in pulp solutions can combine with lead on the cerussite surface to form $\mathrm{PbCl}^{+}$, which acts as the dominant species of lead chloride complexes in the pulp solution, and adsorbed onto the mineral surface and formed a lead-rich surface. Second, even the carbonate ions $\left(\mathrm{CO}_{3}{ }^{2-}\right)$ with the inner cerussite can be exchanged by chloride ions [11-13]. All of these pathways result in increased lead concentrations on the mineral surface (i.e., increased number of active sites), which was revealed by the change of zeta potential. This result corresponded well with the dissolution experiments. 


\subsection{XPS Studies}

XPS, as a sensitive surface technique, can identify the valence state and chemical composition of targeted elements on the measured mineral surface according to the difference in the binding energy of inner electrons from each element. In this study, XPS analysis was employed to further illustrate the increased activity on the cerussite surface induced by chloride ions. The peak fitting and separation was applied to analyze the collected XPS spectra, and the MultiPak Spectrum software was used to determine the relative contents of different compositions in the targeted elements through removal of the contaminated component. The $\mathrm{C} 1 \mathrm{~s}, \mathrm{O} 1 \mathrm{~s}$, and $\mathrm{Pb} 4 \mathrm{f}$ XPS spectra for the mineral surface before and after being treated with chloride ions were analyzed in the present study.

Figures $3 \mathrm{a}$ and $4 \mathrm{a}$ illustrate the $\mathrm{C}$ 1s and $\mathrm{O} 1 \mathrm{~s}$ spectra for the mineral surface treated without chloride ions, respectively. The $\mathrm{C} 1 \mathrm{~s}$ spectrum presented three well-separated XPS peaks positioned at 284.80, 286.30, and $289.28 \mathrm{eV}$ (see Figure 3a). Combined with previous research [26-28], for C 1s spectrum, the chemical state at 284.80 and $286.30 \mathrm{eV}$ XPS peaks were attributed to the contaminated carbon (i.e., hydrocarbon and carbon-oxygen species), and the other XPS peak at $289.28 \mathrm{eV}$ was assigned to the carbon in the carbonate group. The two XPS peaks at 531.42 and $533.16 \mathrm{eV}$ fit the $\mathrm{O}$ ls spectrum (see Figure 4a), which were assigned to the oxygen in the carbonate group and contaminated carbon-oxygen species on the cerussite surface treated without chloride ions. Thus, the authentic contributors to the $\mathrm{C}$ and $\mathrm{O}$ components of the measured sample were positioned at 289.28 and $531.42 \mathrm{eV}$, respectively. This analysis result was also for other samples treated with chloride ions.
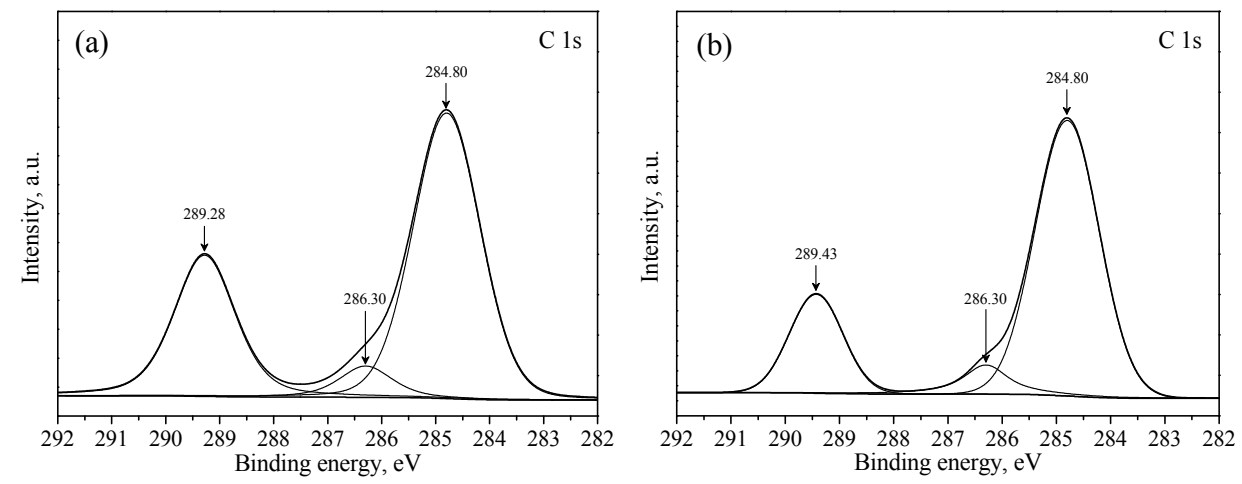

Figure 3. $\mathrm{C}$ 1s spectra for the mineral surface treated with chloride ions: (a) before; (b) after.
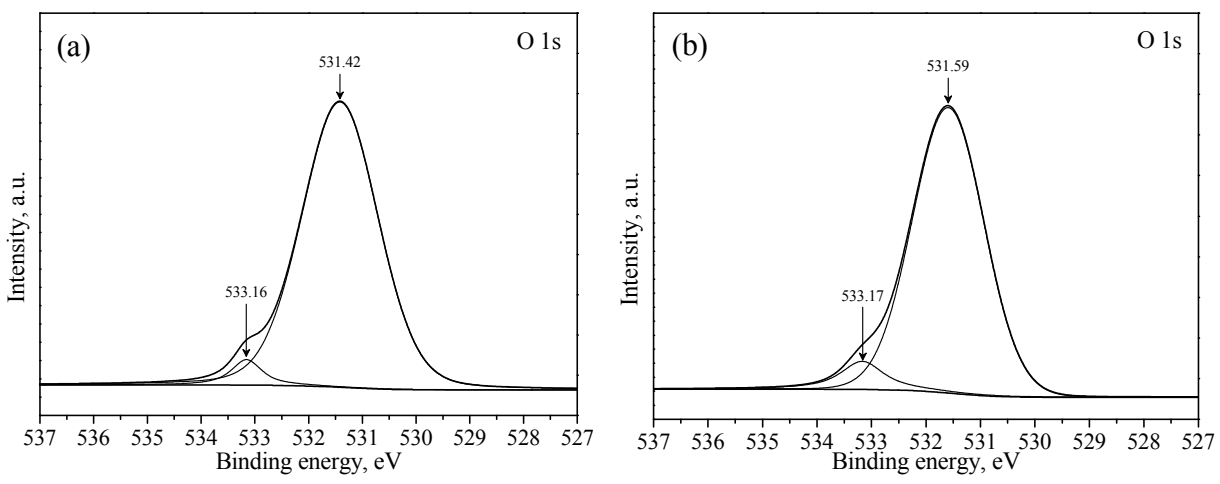

Figure 4. O 1s spectra for the mineral surface treated with chloride ions: (a) before; (b) after.

Table 2 presents the atomic concentrations of cerussite samples before and after being treated with chloride ions. The data revealed that the atomic concentrations of $\mathrm{C}$ and $\mathrm{O}$ in untreated samples were $19.31 \%$ and $60.45 \%$, respectively. The atomic concentrations of $\mathrm{C}$ and $\mathrm{O}$ on the mineral surface treated with chloride ions decreased to $18.11 \%$ and $58.93 \%$, respectively. Table 3 shows the binding energy of each element from cerussite samples before and after being treated with chloride ions. 
As shown in Figures $3 \mathrm{~b}$ and $4 \mathrm{~b}$ and Tables 2 and 3, the binding energy of $\mathrm{C} 1 \mathrm{~s}$ and $\mathrm{O}$ 1s XPS peaks in the carbonate group were 289.43 and $531.59 \mathrm{eV}$, respectively, in mineral surfaces treated with chloride ions. Compared with the result of cerussite treated without chloride ions, the binding energy of $\mathrm{C} 1 \mathrm{~s}$ and $\mathrm{O} 1 \mathrm{~s}$ peaks shifted from 289.28 to 289.43 and from 531.42 to $531.59 \mathrm{eV}$, respectively. These results indicated that the concentration decrease in the carbonate group on the mineral surface occurred when cerussite was pretreated with chloride ions.

Table 2. Atomic concentration of cerussite samples treated with chloride ions: (a) before; (b) after.

\begin{tabular}{cccccccc}
\hline \multirow{2}{*}{ Samples } & \multicolumn{3}{c}{ Atomic Concentration, $\%$} & & \multicolumn{2}{c}{ Atomic Concentration Ratio } \\
\cline { 2 - 3 } \cline { 7 - 8 } & $\mathbf{C ~ 1 s}$ & $\mathbf{O} \mathbf{~ 1 s}$ & $\mathbf{P b} \mathbf{~ f ~}$ & & $\mathbf{P b} / \mathbf{C}$ & $\mathbf{P b} / \mathbf{O}$ \\
\hline $\mathrm{a}$ & 19.31 & 60.45 & 20.23 & & 1.05 & 0.33 \\
$\mathrm{~b}$ & 18.11 & 58.93 & 22.96 & & 1.27 & 0.39 \\
\hline
\end{tabular}

Table 3. Binding energy of each element from various cerussite samples treated with chloride ions: (a) before; (b) after.

\begin{tabular}{|c|c|c|c|c|c|c|}
\hline \multirow{2}{*}{ Samples } & \multicolumn{3}{|c|}{ Binding Energy, eV } & \multicolumn{3}{|c|}{ Chemical Shift, eV } \\
\hline & C 1s & O 1s & $\mathrm{Pb} 4 \mathrm{f}$ & C 1s & O 1s & $\mathrm{Pb} 4 \mathrm{f}$ \\
\hline a & 289.28 & 531.42 & 138.81 & - & - & - \\
\hline$b$ & 289.43 & 531.59 & 138.95 & 0.15 & 0.17 & 0.14 \\
\hline
\end{tabular}

Figure 5a,b illustrates the $\mathrm{Pb} 4 \mathrm{f}$ spectra for the mineral surface before and after being treated with chloride ions, respectively. A single and symmetric $\mathrm{Pb} 4 \mathrm{f}_{7 / 2}$ and $\mathrm{Pb} 4 \mathrm{f}_{5 / 2}$ doublet appeared in the $\mathrm{Pb} 4 \mathrm{f}$ spectrum, and the property of the $\mathrm{Pb} 4 \mathrm{f}_{5 / 2}$ and $\mathrm{Pb} 4 \mathrm{f}_{7 / 2}$ peaks was identical (see Figure $5 \mathrm{a}$ ). The $\mathrm{Pb}$ $4 \mathrm{f}_{7 / 2}$ XPS peak at a binding energy of $138.81 \mathrm{eV}$ was assigned to $\mathrm{PbCO}_{3}[26,29,30]$. Combined with the data in Table 3, the binding energy of $\mathrm{Pb} 4 \mathrm{f}_{7 / 2}$ XPS peak had a shift of $0.14 \mathrm{eV}$ after cerussite was pretreated with chloride ions. The atomic concentrations of $\mathrm{Pb}$ on the mineral surface were $20.23 \%$ and $22.96 \%$, respectively, before and after cerussite was treated with chloride ions (see Table 2), indicating an increase in the atomic concentrations of $\mathrm{Pb}$ on the chloride ion-treated cerussite surface. The $\mathrm{Pb}$ sites on the mineral surface, as active sites, interact with sulfide ions in the pulp solution in the subsequent sulfidization process. Thus, the increase in active sites on the mineral surface provides a favorable condition for the subsequent sulfidization and flotation of cerussite.
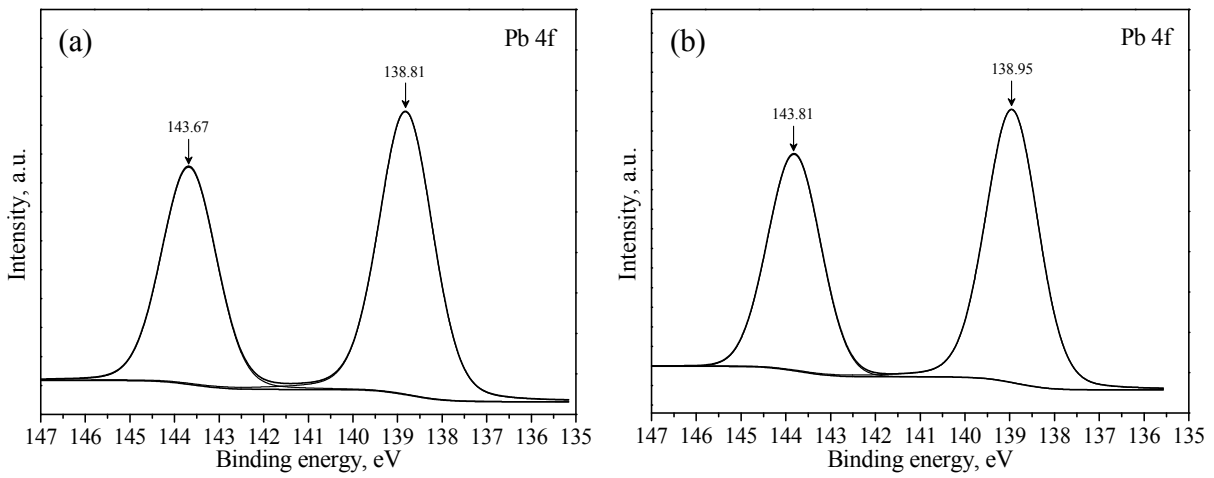

Figure 5. $\mathrm{Pb} 4 \mathrm{f}$ spectra for the mineral surface treated with chloride ions: (a) before; (b) after.

\subsection{DFT Computation}

It has been reported in our previous publication [11] that the distributions of different lead chloride complexes depend on the chloride ion concentration in the solution, and the dominant species 
of lead chloride complexes is $\mathrm{PbCl}^{+}$at low concentrations of chloride ions. In the present study, the adsorption of $\mathrm{PbCl}^{+}$on the cerussite (110) surface was investigated and its adsorption configuration is shown in Figure 6. After $\mathrm{PbCl}^{+}$was adsorbed onto the mineral surface, $\mathrm{Cl}$ atoms bonded to $\mathrm{Pb} 2$ atom on the mineral surface; meanwhile, the $\mathrm{Pb}$ atoms in $\mathrm{PbCl}^{+}$can be stably adsorbed to the mineral surface, thereby increasing the number of $\mathrm{Pb}$ atoms on the mineral surface (i.e., the number of active sites on the cerussite surface increased), which corresponded well with the experimental results.

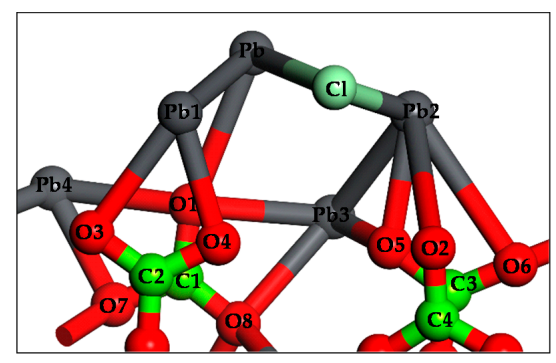

Figure 6. Adsorption configurations of $\mathrm{PbCl}^{+}$on perfect cerussite (110) surface.

The density of states of $\mathrm{Cl}$ atom and its bonded $\mathrm{Pb}$ atom after $\mathrm{PbCl}^{+}$was adsorbed onto the cerussite surface were analyzed to investigate the adsorption behavior of $\mathrm{PbCl}^{+}$and its effects on electronic structure and properties on the cerussite surface. The results are shown in Figure 7. The density of states near the Fermi level was attributed to the $\mathrm{Pb} 6 \mathrm{p}$ and $\mathrm{Cl} 3 \mathrm{p}$ orbital, and the $\mathrm{Pb} 6 \mathrm{p}$ and $\mathrm{Cl} \mathrm{3p}$ orbital were overlapped between -2.0 and $3.5 \mathrm{eV}$ (see Figure 7), indicating the formation of a strong bond between them (i.e., a stable adsorption of $\mathrm{PbCl}^{+}$occurred on the mineral surface), increasing the number of $\mathrm{Pb}$ atoms on the cerussite surface. The density of states of $\mathrm{Pb}$ atoms for perfect cerussite (110) surface before and after $\mathrm{PbCl}^{+}$adsorption was compared and discussed to further illustrate the change of electronic structure and properties on the mineral surface. A pronounced change occurred in the shape of the density of states for $\mathrm{Pb}$ atoms after $\mathrm{PbCl}^{+}$was adsorbed onto the mineral surface and the peak intensity of the density of states for $\mathrm{Pb}$ atoms improved (see Figure 8). Moreover, the peaks shifted to the Fermi level, revealing that the activity of $\mathrm{Pb}$ atoms on the mineral surface was enhanced after $\mathrm{PbCl}^{+}$was adsorbed onto the mineral surface. This result provided another reason for the contribution of chloride ions to the surface properties of cerussite.

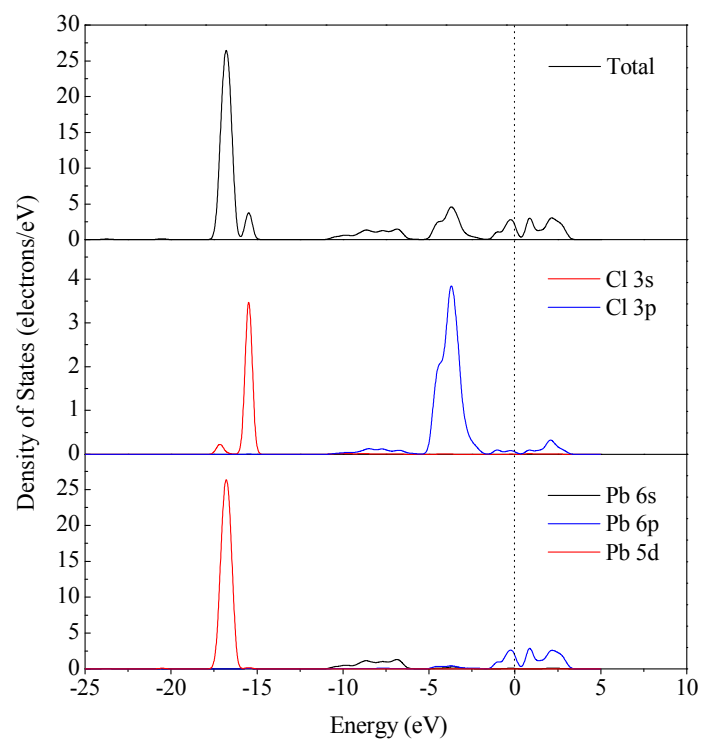

Figure 7. Density of state of atoms for cerussite surface after $\mathrm{PbCl}^{+}$adsorption. 


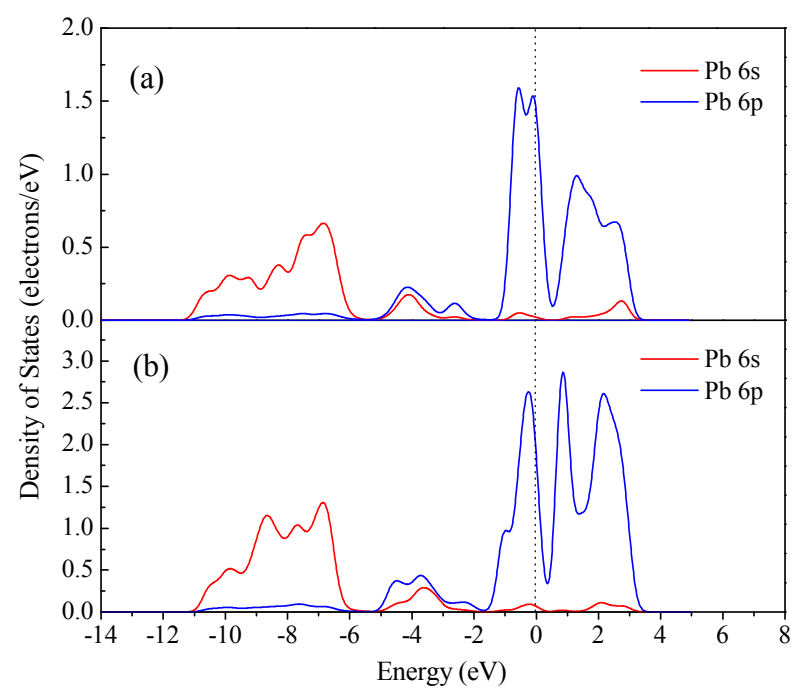

Figure 8. Density of state of $\mathrm{Pb}$ atoms for perfect cerussite surface: (a) before; (b) after $\mathrm{PbCl}^{+}$adsorption.

\section{Conclusions}

The mechanisms of increased activity on the cerussite surface induced by chloride ions were investigated through dissolution experiments, zeta potential measurements, XPS analysis, and DFT computation. The results of dissolution experiments indicated that the number of active sites on the mineral surface increased after cerussite was pretreated with chloride ions based on the changes of the lead ion concentrations in various solution systems. The increase in zeta potential on the mineral surface implied that the numbers of lead ion species increased through the migration of lead ion species from aqueous solutions to the mineral surface. The XPS analysis results visually attest that the atomic concentrations of $\mathrm{C}$ and $\mathrm{O}$ decreased and the atomic concentration of $\mathrm{Pb}$ increased on the cerussite surface treated with chloride ions compared with the results without chloride ions. These complementary surface analysis techniques consistently revealed that the pretreatment of the cerussite surface with chloride ions resulted in an increase in the number of active sites. The DFT results indicated that both the number of active sites and the activity of active sites on the mineral surface increased and improved, which was beneficial to the subsequent sulfidization and flotation of cerussite. These analysis results provided an integrated and comprehensive theoretical foundation for the contribution of chloride ions to the sulfidization flotation of cerussite.

Acknowledgments: The authors would like to acknowledge the financial support provided by the National Natural Science Foundation of China (No. 51464029).

Author Contributions: Qicheng Feng and Shuming Wen conceived and designed the experiments; Qicheng Feng and Wenjuan Zhao performed the experiments; Qicheng Feng and Qinbo Cao analyzed the data; Jiushuai Deng contributed DFT computation; Qicheng Feng wrote the paper.

Conflicts of Interest: The authors declare no conflict of interest.

\section{References}

1. Li, Y.; Wang, J.K.; Wei, C.; Liu, C.X.; Jiang, J.B.; Wang, F. Sulfidation roasting of low grade lead-zinc oxide ore with elemental sulfur. Miner. Eng. 2010, 23, 563-566. [CrossRef]

2. Li, C.X.; Wei, C.; Deng, Z.G.; Li, X.B.; Li, M.T.; Xu, H.S. Hydrothermal sulfidation and flotation of oxidized zinc-lead ore. Metall. Mater. Trans. B 2014, 45, 833-838. [CrossRef]

3. Feng, Q.C.; Wen, S.M.; Wang, Y.J.; Zhao, W.J.; Deng, J.S. Investigation of leaching kinetics of cerussite in sodium hydroxide solutions. Physicochem. Probl. Miner. Process. 2015, 51, 491-500.

4. Fa, K.Q.; Miller, J.D.; Jiang, T.; Li, G.H. Sulphidization flotation for recovery of lead and zinc from oxide-sulfide ores. Trans. Nonferr. Met. Soc. China 2005, 15, 1138-1144. 
5. Gush, J.C.D. Flotation of oxide minerals by sulphidization-The development of a sulphidization control system for laboratory testwork. J. S. Afr. Inst. Min. Metall. 2005, 105, 193-197.

6. Feng, Q.C.; Wen, S.M.; Zhao, W.J.; Liu, J.; Liu, D. Effect of $\mathrm{pH}$ on surface characteristics and flotation of sulfidized cerussite. Physicochem. Probl. Miner. Process. 2016, 52, 676-689.

7. Yuan, W.Y.; Li, J.H.; Zhang, Q.W.; Saito, F. Mechanochemical sulfidization of lead oxides by grinding with sulfur. Powder Technol. 2012, 230, 63-66. [CrossRef]

8. Ke, Y.; Chai, L.Y.; Liang, Y.J.; Min, X.B.; Yang, Z.H.; Chen, J.; Yuan, S. Sulfidation of heavy-metal-containing metallurgical residue in wet-milling processing. Miner. Eng. 2013, 53, 136-143. [CrossRef]

9. Ke, Y.; Chai, L.Y.; Min, X.B.; Tang, C.J.; Zhou, B.S.; Chen, J.; Yuan, C.Y. Behavior and effect of calcium during hydrothermal sulfidation and flotation of zinc-calcium-based neutralization sludge. Miner. Eng. 2015, 74, 68-78. [CrossRef]

10. Han, H.S.; Sun, W.; Hu, Y.H.; Jia, B.L.; Tang, H.H. Anglesite and silver recovery from jarosite residues through roasting and sulfidization-flotation in zinc hydrometallurgy. J. Hazard. Mater. 2014, 278, 49-54. [CrossRef] [PubMed]

11. Feng, Q.C.; Wen, S.M.; Zhao, W.J.; Wang, Y.J.; Cui, C.F. Contribution of chloride ions to the sulfidization flotation of cerussite. Miner. Eng. 2015, 83, 128-135. [CrossRef]

12. Bargar, J.R.; Brown, G.E.; Parks, G.A. Surface complexation of $\mathrm{Pb}(\mathrm{II})$ at oxide-water interfaces: III. XAFS determination of $\mathrm{Pb}(\mathrm{II})$ and $\mathrm{Pb}(\mathrm{II})$-chloro adsorption complexes on goethite and alumina. Geochim. Cosmochim. Acta 1998, 62, 193-207. [CrossRef]

13. Guo, Y.B.; Li, C.; Liu, Y.C.; Yu, L.M.; Ma, Z.Q.; Liu, C.X.; Li, H.J. Effect of microstructure variation on the corrosion behavior of high-strength low-alloy steel in $3.5 \mathrm{wt} \% \mathrm{NaCl}$ solution. Int. J. Miner. Metall. Mater. 2015, 22, 604-612. [CrossRef]

14. Antao, S.M.; Hassan, I. The orthorhombic structure of $\mathrm{CaCO}_{3}, \mathrm{SrCO}_{3}, \mathrm{PbCO}_{3}$ and $\mathrm{BaCO}_{3}$ : Linear structural trends. Can. Mineral. 2009, 47, 1245-1255. [CrossRef]

15. Payne, M.C.; Teter, M.P.; Allan, D.C.; Arias, T.A.; Joannopoulos, J.D. Iterative minimization techniques for ab initio total-energy calculations: Molecular dynamics and conjugate gradients. Rev. Mod. Phys. 1992, 64, 1045-1097. [CrossRef]

16. Perdew, J.P.; Ruzsinszky, A.; Csonka, G.I.; Vydrov, O.A.; Scuseria, G.E.; Constantin, L.A.; Zhou, X.L.; Burke, K. Restoring the density-gradient expansion for exchange in solids and surfaces. Phys. Rev. Lett. 2008, 100, 136406. [CrossRef] [PubMed]

17. Powell, K.J.; Brown, P.L.; Byrne, R.H.; Gajda, T.; Hefter, G.; Leuz, A.K.; Sjöberg, S.; Wanner, H. Chemical speciation of environmentally significant metals with inorganic ligands. Part 3: The $\mathrm{Pb}^{2+}+\mathrm{OH}^{-}, \mathrm{Cl}^{-}$, $\mathrm{CO}_{3}{ }^{2-}, \mathrm{SO}_{4}{ }^{2-}$, and $\mathrm{PO}_{4}{ }^{3-}$ systems (IUPAC Technical Report). Pure Appl. Chem. 2009, 81, 2425-2476. [CrossRef]

18. Shirota, Y.; Niki, K.; Shindo, H. Stabilities of crystal faces of aragonite-type strontianite $\left(\mathrm{SrCO}_{3}\right)$ and cerussite $\left(\mathrm{PbCO}_{3}\right)$ compared by AFM observation of facet formation in acid. J. Cryst. Growth 2011, 324, 190-195. [CrossRef]

19. Feng, Q.C.; Wen, S.M.; Zhao, W.J.; Deng, J.S.; Xian, Y.J. Adsorption of sulfide ions on cerussite surfaces and implications for flotation. Appl. Surf. Sci. 2016, 360, 365-372. [CrossRef]

20. Shi, Q.; Zhang, G.F.; Feng, Q.M.; Deng, H. Effect of solution chemistry on the flotation system of smithsonite and calcite. Int. J. Miner. Process. 2013, 119, 34-39. [CrossRef]

21. Feng, B.; Feng, Q.M.; Lu, Y.P. The effect of lizardite surface characteristics on pyrite flotation. Appl. Surf. Sci. 2012, 259, 153-158. [CrossRef]

22. Li, F.X.; Zhong, H.; Xu, H.F.; Jia, H.; Liu, G.Y. Flotation behavior and adsorption mechanism of $\alpha$-hydroxyoctyl phosphinic acid to malachite. Miner. Eng. 2015, 71, 188-193. [CrossRef]

23. Fuerstenau, M.C.; Olivas, S.A.; Herrera-Urbina, R.; Han, K.N. The surface characteristics and flotation behavior of anglesite and cerussite. Int. J. Miner. Process. 1987, 20, 73-85. [CrossRef]

24. Popov, S.R.; Vučinić, D.R. The effect of prolonged agitation in lead ion solution on ethylxanthate adsorption and surface characteristics of cerussite. Int. J. Miner. Process. 1992, 35, 85-100. [CrossRef]

25. Popov, S.R.; Vučinić, D.R. Kinetics of ethylxanthate adsorption on cerussite in alkaline media in presence or absence of dissolved lead ions. Int. J. Miner. Process. 1994, 41, 115-128. [CrossRef]

26. Grano, S.R.; Prestidge, C.A.; Ralston, J. Sulphite modification of galena surfaces and its effect on flotation and xanthate adsorption. Int. J. Miner. Process. 1997, 52, 1-29. [CrossRef] 
27. Buckley, A.N.; Goh, S.W.; Lamb, R.N.; Woods, R. Interaction of thiol collectors with pre-oxidised sulfide minerals. Int. J. Miner. Process. 2003, 72, 163-174. [CrossRef]

28. Nowak, P.; Laajalehto, K. On the interpretation of the XPS spectra of adsorbed layers of flotation collectors-ethyl xanthate on metallic lead. Physicochem. Probl. Miner. Pross. 2007, 41, 107-116.

29. Cozza, C.; Castro, V.D.; Polzonetti, G.; Marabini, A.M. An X-ray photoelectron spectroscopy (XPS) study of the interaction of mercapto-benzo-thiazole with cerussite. Int. J. Miner. Process. 1992, 34, 23-32. [CrossRef]

30. Chanturia, V.A.; Bunin, I.Z.; Ryazantseva, M.V.; Khabarova, I.A.; Koporulina, E.V.; Anashkina, N.E. Surface activation and induced change of physicochemical and process properties of galena by nanosecond electromagnetic pulses. J. Min. Sci. 2014, 50, 573-586. [CrossRef]

(C) 2016 by the authors; licensee MDPI, Basel, Switzerland. This article is an open access article distributed under the terms and conditions of the Creative Commons Attribution (CC-BY) license (http://creativecommons.org/licenses/by/4.0/). 